\title{
NUMERICAL MODELLING OF HYDRODYNAMICS AND SEDIMENT TRANSPORT IN THE SURF ZONE : A SENSITIVITY STUDY WITH DIFFERENT TYPES OF NUMERICAL MODELS
}

\author{
Koen Trouw ${ }^{1}$, Nicolas Zimmermann ${ }^{2}$, Mieke Mathys ${ }^{2}$, Rosalia Delgado ${ }^{3}$, Dano Roelvink ${ }^{4}$
}

A comparison between two very different numerical models is presented: Delft3D and XBeach. Delft3D (Deltares) calculates non-steady flow and transport phenomena that result from tidal and meteorological forcing. The wave propagation is calculated in the frequency domain. XBeach (Unesco-IHE, Delft University and Deltares) consists of formulations for short wave envelope propagation (time-dependent wave action balance), non-stationary shallow water equations, sediment transport and bed update. The model is able to resolve the time dependent long waves, which are important in the surf zone. A number of simplified cases are defined beforehand taking into account actual features and conditions existing in chosen problem areas. The examination of these simplified cases allows for the identification of driving processes and the assessment of the sensitivity to certain relevant parameters, with the advantage of working in scenarios of limited complexity and without excessive computational load.

Keywords: morphological modeling, XBeach, Delft3D, beach dynamics

\section{INTRODUCTION}

The Flemish beaches are sandy (200 to $300 \mu \mathrm{m})$ and have a corresponding slope between 1:40 and 1:80. The beaches are exposed to a tidal range of about $4 \mathrm{~m}$. The typical yearly storm is characterized by a significant wave height of about $4 \mathrm{~m}$ at the shoreface and a peak period of about $9 \mathrm{~s}$. In front of the coast often tidal gullies are present. Along the $67 \mathrm{~km}$ long coast four harbour entrances are present and fields of low groynes stretch up to the LW-line with a height of 0.5 to $1.5 \mathrm{~m}$ above the sand bed. An example in Blankenberge is visible in Figure 1.

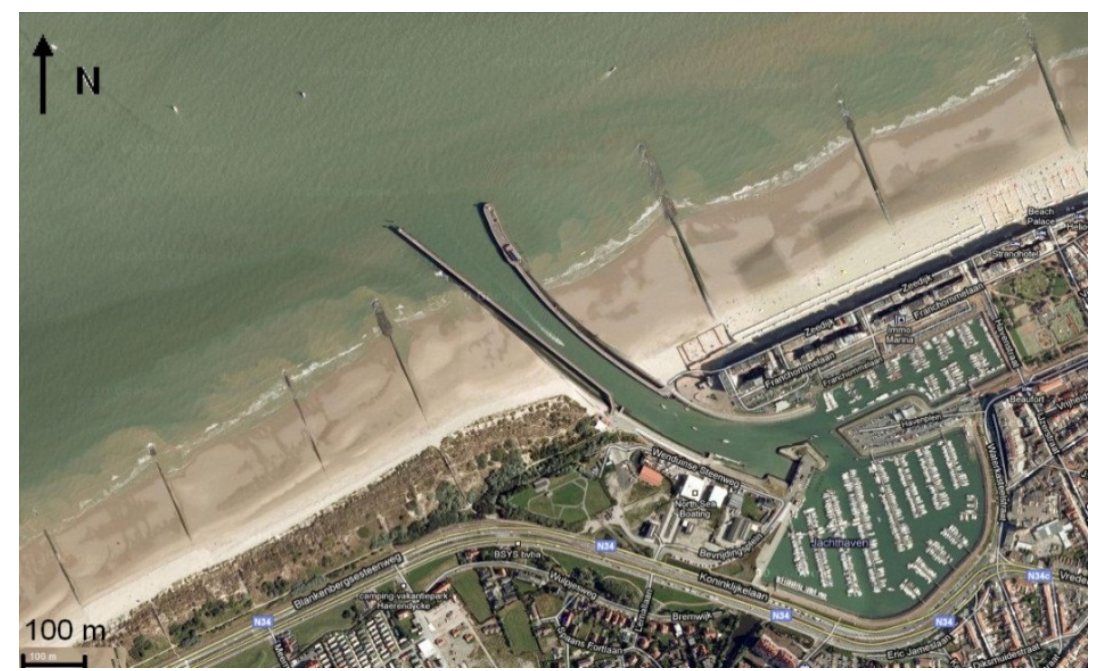

Figure 1 Beaches and harbor entrance of Blankenberge

The beach and shoreface are important parts in the coastal protection of the Flemish Coast. However, their long-term morphological behaviour is a complex result of many processes on different scales in time and space for which a better understanding is needed to uphold the coastal protection in the future in an optimal way. For instance, the efficiency and effectiveness of beach or shoreface nourishments can be optimised when the insight in long-term morphological behaviour of the beach and shoreface is deepened. Detailed numerical modelling of the hydrodynamics (of waves, tidal currents, water levels), sediment transport and changing morphology is the main tool to gain insight in the long-term processes, to predict future changes and to set up an integrated sand policy in the coastal zone.

A simplified model for the area of Blankenberge is set up both in XBeach and in Delft3D. A series of simulations of increased complexity are run initially with default parameters which are modified

\footnotetext{
${ }^{1}$ Fides Engineering,Sint Laureisstraat 69D 2018 Antwerp, Belgium, Koen.Trouw@fidesengineering.be

2 IMDC, Coveliersstraat 152600 Antwerp, Belgium

${ }^{3}$ Flanders Hydraulics Research, Berchemlei 115, 2140 Antwerp, Belgium

${ }^{4}$ UNESCO-IHE Institute for Water Education, PO Box 30152601 DADelft, the Netherlands
} 
only when model results indicated that other values should be used. Each main output parameter is compared then in 1D plots and 2D maps, from which discrepancies are analyzed and interpreted.

\section{METHODOLGY}

The methodology followed for this study is based in two steps: first a simplification of the actual situation is implemented in both models in order to look at main processes and assess whether these are really relevant or not for the investigation of the problem. In a second step, simulations of the real situation, with actual bathymetry, boundary conditions etc will be carried out.

The simplified model consists of a coast uniform alongshore with a cross-shore profile representative of reality. The port is modelled by an entrance channel dredged to its design depth and protected by a groyne on each side. The groynes are perpendicular to the coastline, sloping from the landward boundary until the low water line $(0 \mathrm{~m}$ below $\mathrm{CD})$ and have a constant height above the local sea bed.

Simulations without structures are run first with waves only, tide alone, and waves and tides combined. Then structures are added progressively: first one groyne, then two groynes and finally the harbour entrance channel. The existing piers are not included in the model. The simulations are run over two tidal cycles, first with hydrodynamics and sediment transport during the first tidal cycle, then with morphology during the second tidal cycle. This approach allows to compare methodically the model results and to isolate causes of differences observed, without the influence of bathymetrical changes during the first tidal cycle.

\section{DESCRIPTION OF THE USED MODELS}

\section{XBeach}

$\mathrm{XBeach}$ is a 2D morphological model developed to assess the natural coastal response to timevarying storm and hurricane conditions, including dune erosion, overwash and breaching. It applies a non-stationary long wave flux at the boundary, which then serves to solve the propagation of the short wave envelope, the non-stationary shallow water equations, sediment transport and bed update. Avalanching is used to compute dune erosion and cross-shore transport relies on a special formulation to compute the balance between onshore sediment transport by wave skewness and asymmetry and offshore transport by the return flow. The wave solver used is based on the second generation HISWA model. Details about the XBeach model can be found in Roelvink et al. (2009) and the user manual (Unesco-IHE, 2009):

The model consists of formulations for short wave averaged envelope propagation, non-stationary shallow water equations, sediment transport and bed update. Innovations include a newly developed time-dependent wave action balance solver, which solves the wave refraction and allows variation of wave action in $\mathrm{x}, \mathrm{y}$, time and over the directional space, and can be used to simulate the propagation and dissipation of wave groups. XBeach can be uses for swash and overwash, during erosion and inundation modeling.

An added advantage to this setup, compared to the existing surfbeat (infragravity wave) model, is that a separate wave model is not needed to predict the mean wave direction, and it allows different wave groups to travel in different directions. Full wave-current interaction in the short wave propagation is included. Roelvink (1993) wave dissipation model is implemented for use in the nonstationary wave energy balance (in other words, when the wave energy varies on the wave group timescale).

The Generalised Lagrangean Mean (GLM) approach was implemented to represent the depthaveraged undertow and its effect on bed shear stresses and sediment transport, cf. Reniers et al. (2004).

The Soulsby - Van Rijn transport formulations have been included, which solve the 2DH advection-diffusion equation and produce total transport vectors, which can be used to update the bathymetry. The pickup function following Reniers et al (2004) was implemented. An avalanching routine was implemented with separate criteria for critical slope at wet or dry points providing a smooth and robust solution for slumping of sand during dune erosion.

The model has been validated with a series of analytical, laboratory and field test cases showing toperform well in different situations including dune erosion, overwash and breaching modelled using a standard set of parameter settings.

XBeach is open source (www.XBeach.org). 


\section{Delf3D}

Delft3D is a modelling package which consists of several modules to compute amongst other the flow (FLOW), wave (WAVE) and morphology (MOR, included in FLOW) in coastal waters. The FLOW module solves the depth-averaged or 3D shallow water equations on a rectilinear or curvilinear grid. In the WAVE module, the wave transformation is computed by the third-generation wave model SWAN (Booij et al., 1999; Ris et al., 1999). It includes wave propagation, generation by wind, nonlinear wave-wave interaction and dissipation. The WAVE and FLOW modules are coupled online at regular interval to account for the effects of waves on the flow and to provide flow boundary conditions for the wave transformation. Sediment transport under combined waves and currents is computed with an advection-diffusion equation and morphology can be sped up with a morphological acceleration factor (morfac). More details about the Delft3D model can be found in Lesser et al. (2004).

Delft3D is an open source code (http://oss.deltares.nl/web/opendelft3d).

\section{MODEL SET UP}

All simulations are done on a domain with a rectilinear coastline and constant slope. The mean sea level (MSL) is set at $2.25 \mathrm{~m} \mathrm{CD}$. Neap, average and spring tide conditions are respectively simulated by a tidal amplitude of $2.5 \mathrm{~m}, 3.5 \mathrm{~m}$ and $4.5 \mathrm{~m}$. Calm conditions are represented by a significant wave height of $1 \mathrm{~m}$, storm conditions by a significant wave height of $3 \mathrm{~m}$. The peak period is always $8 \mathrm{~s}$. All waves come from the NW quadrant. The wave incidence angle $(\alpha)$ is given with respect to the North. The wave spectrum has a directional resolution of $10^{\circ}$ in both models and the frequency covers 10 bins ranging from 0.07 to $0.4 \mathrm{~Hz}$ in Delft3D. Frequency bins are determined internally in XBeach. Wave conditions nearer to the shore as applied in XBeach are taken from Delft3D results at that distance. The sediment size is $200 \mu \mathrm{m}$.

Paragraphs below describe the settings for Xbeach and Delft3D.

\section{Delft3D}

Figure 2 shows the flow and wave grid in Delft3D. The wave grid has been chosen larger than the flow grid to prevent lateral boundary effects.

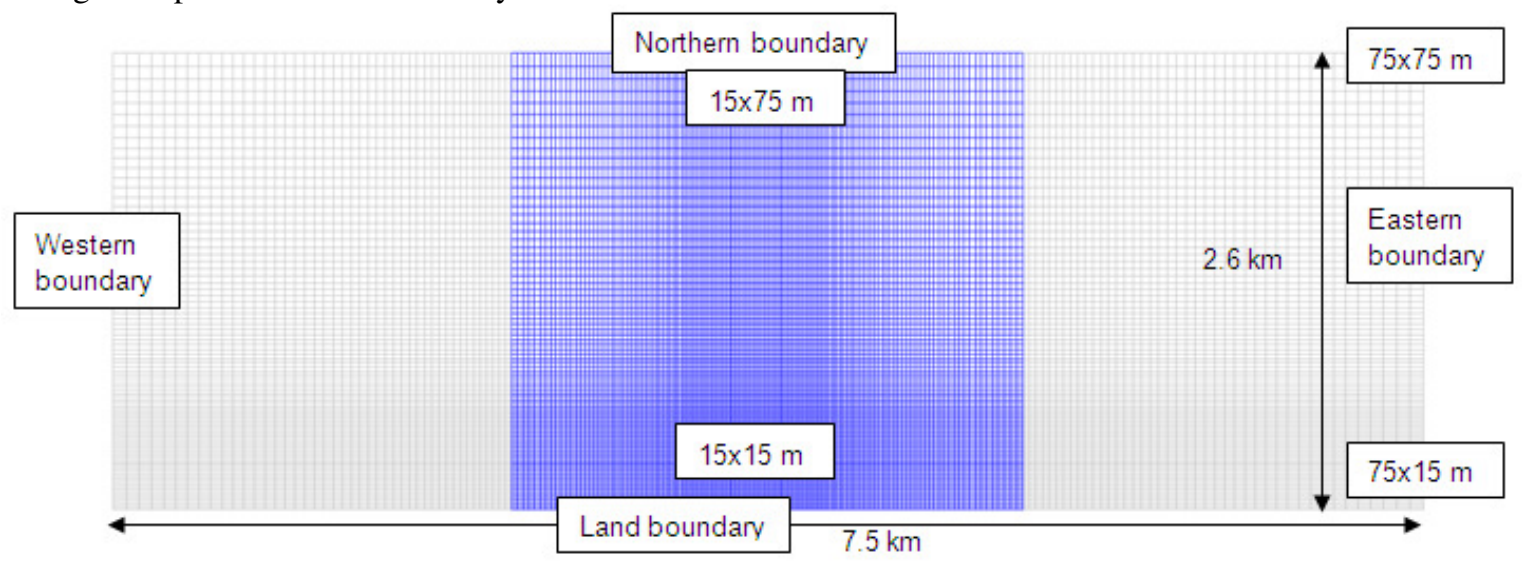

Figure 2 FLOW grid (blue) and WAVE grid (grey) resolution and dimensions.

Figure 3 shows the bathymetry applied in the flow model. The bathymetry in the wave model is simply extended alongshore. 


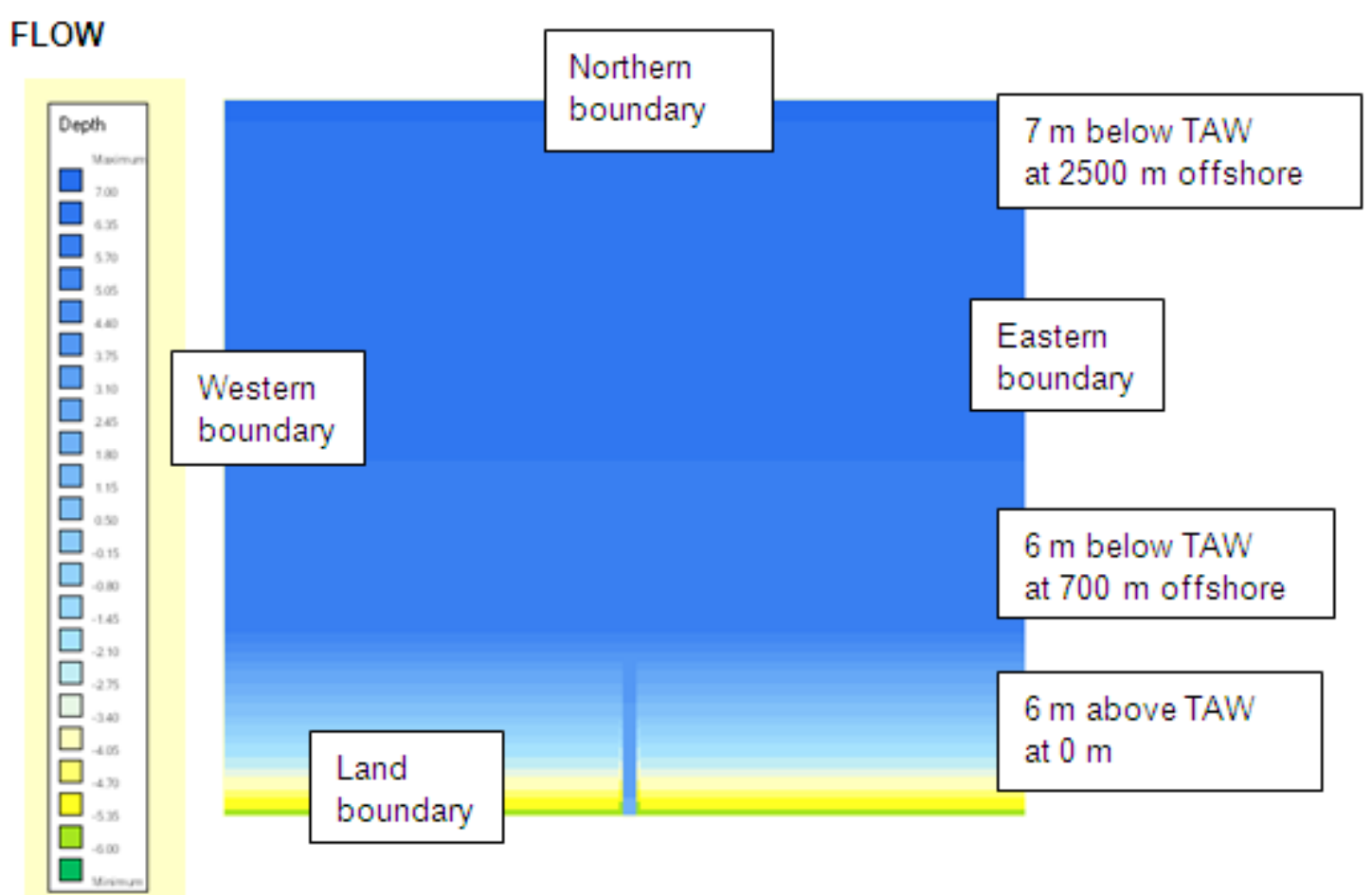

Figure 3 Bathymetry of the FLOW grid in the simplified model, with the deeper entrance channel (blue) intersecting the uniform coast (yellow).

Some parameters have been changed from their default values based on experience and on a sensitivity analysis of Delft3D. The wave-related transport factors for bed-and suspended load are set to zero to prevent the formation of unrealistic cross-shore profiles (high berms near the coast line). Default settings for viscosity and diffusivity coefficient are judged too high for coastal applications and are reduced respectively from 1 and $10 \mathrm{~m}^{2} / \mathrm{s}$ to 0.1 and $0.1 \mathrm{~m}^{2} / \mathrm{s}$. They respectively determine the smoothness of the vector and scalar fields. Depths are defined in the cell centre instead of the corners to prevent numerical artifacts in areas of coarse resolution such as near the groynes. The keyword CstBnd has been turned on to prevent the formation of artificial boundary layers along the domain boundaries (Deltares, 2010a; p. 220). These may occur due to normal components of the advection terms. Finally in the WAVE module, FLOW results of the bathymetry, the current and the water level are used and extended to the larger WAVE grid. It implies in particular the use of wave-current interaction processes.

\section{XBeach}

The XBeach model uses the same grid and bathymetry as Delft3D-FLOW but cropped at $900 \mathrm{~m}$ offshore to reduce computation time and becausethe wave model used in XBeach misses some offshore processes such as quadruplet wave-wave interaction and wind growth. The tide is schematized in the same way, while instationary waves applied at the offshore boundary are derived from an output spectrum from Delft3D at this distance from the coast. The wave spectrum discretisation has a directional resolution of $10^{\circ}$ and ranges from $-90^{\circ}$ to $+90^{\circ}$ nautical (all directions towards the coast).

The morphology is also computed without acceleration factor after a spin-up time of one tidal cycle in order to first analyze hydrodynamics alone. Currents need approximately four hours to adapt to the water level forcing and hence do not influence the results. The used sediment size is d50 $=200 \mu \mathrm{m}$ and $\mathrm{d} 90=300 \mu \mathrm{m}$.

All options are kept to their default values, which in our experience yield reasonable results for the present application. These default values are sometimes in contradiction to those of Delft3D: they do for instance not include wave-current interaction and bottom friction. The output is averaged every 30 min to counterbalance the instationary character and compare the results.

Results presented in this paper are output of the Eastern2012-version of Xbeach. 
COMPARISON OF PHYSICAL PROCESSES INCORPORATED IN XBEACH AND DELFT3D

Wave modeling

The concept of wave modeling is different for both models: in XBeach the wave envelope/long waves are modeled in the time domain, whereas in Delft3D the short waves are modeled in the frequency domain; XBeach is instationary, Delft3D stationary. XBeach is not intended for deep sea conditions (e.g. no wind input), for this Delft3D is more suitable.

Sediment transport processes

The formulations for longshore transport are comparable in both models. However, for cross shore transport differences are large. The next paragraph describes shortly the physics of cross shore transport and the performance of Delft3D (in 2D mode) and Xbeach.

In Table 1 an overview is given of all relevant cross shore processes, summarizing literature (Ruessink et al, 2007, Grasmeijer, 2002, Walstra, 2012). In column 2 to 4 the relative importance of each process for resp. onshore, offshore transport and bar behavior is given (1: relative less important, 4 : relative most important, - : not relevant). The last two columns summarize to which extent Delft3D $(2 \mathrm{DH})$ and $\mathrm{XBeach}$ incorporate these processes.

\begin{tabular}{|c|c|c|c|c|c|}
\hline Process & $\begin{array}{l}\text { Rel. imp } \\
\text { Onshore }\end{array}$ & $\begin{array}{l}\text { Rel. imp } \\
\text { Offshore }\end{array}$ & $\begin{array}{l}\text { Rel. imp } \\
\text { Bar } \\
\text { behaviour }\end{array}$ & Delft3D & XBeach \\
\hline Stokes' drift & 1 & - & 1 & No & No \\
\hline Return flow & - & 4 & 4 & $\begin{array}{c}\text { No } \\
\text { (hydrodynamics } \\
\text { only) }\end{array}$ & Yes \\
\hline Streaming & 1 & - & 1 & Yes (in bed load) & No \\
\hline $\begin{array}{l}\text { Wave } \\
\text { asymmetry }\end{array}$ & 3 & - & 3 & No & $\begin{array}{c}\text { Yes (in } \\
\text { suspended load) }\end{array}$ \\
\hline $\begin{array}{l}\text { Wave } \\
\text { skewness }\end{array}$ & 4 & - & 4 & Yes (in bed load) & $\begin{array}{c}\text { Yes (in } \\
\text { suspended load) }\end{array}$ \\
\hline $\begin{array}{l}\text { In- and } \\
\text { Exfiltration }\end{array}$ & 1 & 1 & 1 & No & $\begin{array}{c}\text { No } \\
\text { (hydrodynamics } \\
\text { only) }\end{array}$ \\
\hline Gravity & - & 2 & 3 & $\begin{array}{c}\text { Yes (correction } \\
\text { of bed load } \\
\text { transport) }\end{array}$ & $\begin{array}{l}\text { Yes (correction } \\
\text { of equil. } \\
\text { concentration) }\end{array}$ \\
\hline Turbulence & 2 & 2 & 3 & No & No \\
\hline Wind stress & 1 & 1 & 1 & No* & No* \\
\hline $\begin{array}{l}\text { Settling } \\
\text { velocity }\end{array}$ & 1 & 1 & 1 & $\mathrm{No}^{* *}$ & $\mathrm{No}^{* *}$ \\
\hline Bed forms & 1 & 1 & 2 & Yes (predictor) & $\begin{array}{l}\text { Limited (initial } \\
\text { conditions only) }\end{array}$ \\
\hline Long waves & 1 & 4 & 4 & $\mathrm{No}$ & Yes \\
\hline Wave roller & - & - & 3 & $\begin{array}{l}\text { Limited (not } \\
\text { convenient) }\end{array}$ & Yes \\
\hline 3D effects & - & - & 2 & $\begin{array}{c}\text { Limited } \\
\text { (longshore } \\
\text { current and wind } \\
\text { only) }\end{array}$ & Yes \\
\hline
\end{tabular}

* A wind field can be added but a 3D model would be required to model the cross-shore recirculation ; longshore flow forcing possible

** No intrawave lag effects, only underloading / overloading of suspended sediment 
For modelling purpose cross-shore transport can be reduced to a minimum number of dominant processes:

- Table 1 and attempts to model bar growth found in literature (e.g. Grasmeijer, 2002; Ruessink et al, 2007) suggest that the dominant processes for onshore and offshore transport are respectively wave non-linearity (skewness in the shoaling zone, asymmetry in the surf zone) and the return flow (combined to turbulent mixing).

- The growth and migration of a bar is probably the most sensitive point since it requires sediment transport to converge on or around the top of the bar, directed onshore from the sea and offshore from the beach. The location of this convergence point in return strongly depends on the wave roller and on the concentration profile via turbulence, and possibly via bed forms and 3D effects.

- Dune erosion by long waves and avalanching is critical to supply the underwater profile with sediment during storm and to create a bar. This in turn may require a robust drying and wetting scheme.

Based on this table and literature, the following conclusions can be drawn about the incorporated physical processes inXBeach and Delft3D :

- Delft3D is not suitable to model bar behaviour with a 2D model, primarily because dune erosion by long waves and offshore sediment transport by the return flow are not included. A 3D model has been shown to perform better (Brière, 2006) but would still miss dune erosion. XBeach on the other hand includes all main processes necessary to model bar behaviour, with the exception of the effect of vertical mixing by wave breaking turbulence on the relative importance of onshore-directed transport by wave non-linearity and offshore-directed transport by the return flow.

- In Delft3D, due to the way bed load and suspended transport have been implemented, waverelated transport in $2 \mathrm{DH}$ is always onshore and the only possible offshore-directed components are bed slope effects or suspended sediment diffusion. The effect of the return flow on sediment transport requires a 3D model. Since the bed slope effect scales on the bed load transport, if the wave-related scaling factors are set to zero, it is also zero. The diffusion component on the other hand is one to two orders of magnitude lower than the advection component, which explains why its effect is not visible (Zimmermann et al, 2012).

- In addition, in Delft3D the default values for wave-related bed load and suspended load factors are too high and lead to an unrealistic steepening of the coastal profile. Values of 0 to 0.1 instead of 1 are suggested.

- The popular alternative approach of Bailard (1981) implemented in Delft3D in the transport formulae of Bijker (1971) may allow to get a tuneable balance between onshore transport by wave asymmetry and offshore transport by bed slope effects, however without return flow the physics of the model are still likely flawed.

\section{RESULTS OF THE SENSITIVITY ANALYSIS}

Paragraphs below summarise the conclusions from the modeling of the simplified case. First the conclusions are given for both models separately and then for the comparison of the two models.

\section{Delft3D}

The directional resolution (varied between 2 and 10 degrees) does not influence the computed mean wave direction (nor the other results). However the peak wave direction only takes discrete values in the directional bins of the initial discretization and cannot be used with a too coarse resolution. The same remark may be made for other "peak" parameters such as the peak wave period.

The non-zero mean wave direction for waves normal to and close to the coast in Delft3D is an inaccuracy which decreases with increasing directional resolution. The error is acceptable.

In the absence of wind, turning on dissipation by whitecapping does not influence the wave height nor the other results.

Wave-induced currents may be computed with the radiation stress theory (default) or from the wave energy dissipation rate. Using the latter as a wave force leads to a stronger longshore current in the breaker zone (cf Figure 4). In the theory of Longuet-Higgins (1970a,b), the radiation stress is computed from the energy flux multiplied by Snell's law. Without dissipation both terms should be 
constant, which implies that the longshore current should be equal with both formulations. The log file of Delft3D suggests that negative dissipation rates are set to zero and may explain the difference with the radiation stress theory, in which shoaling might be considered as an energy source.

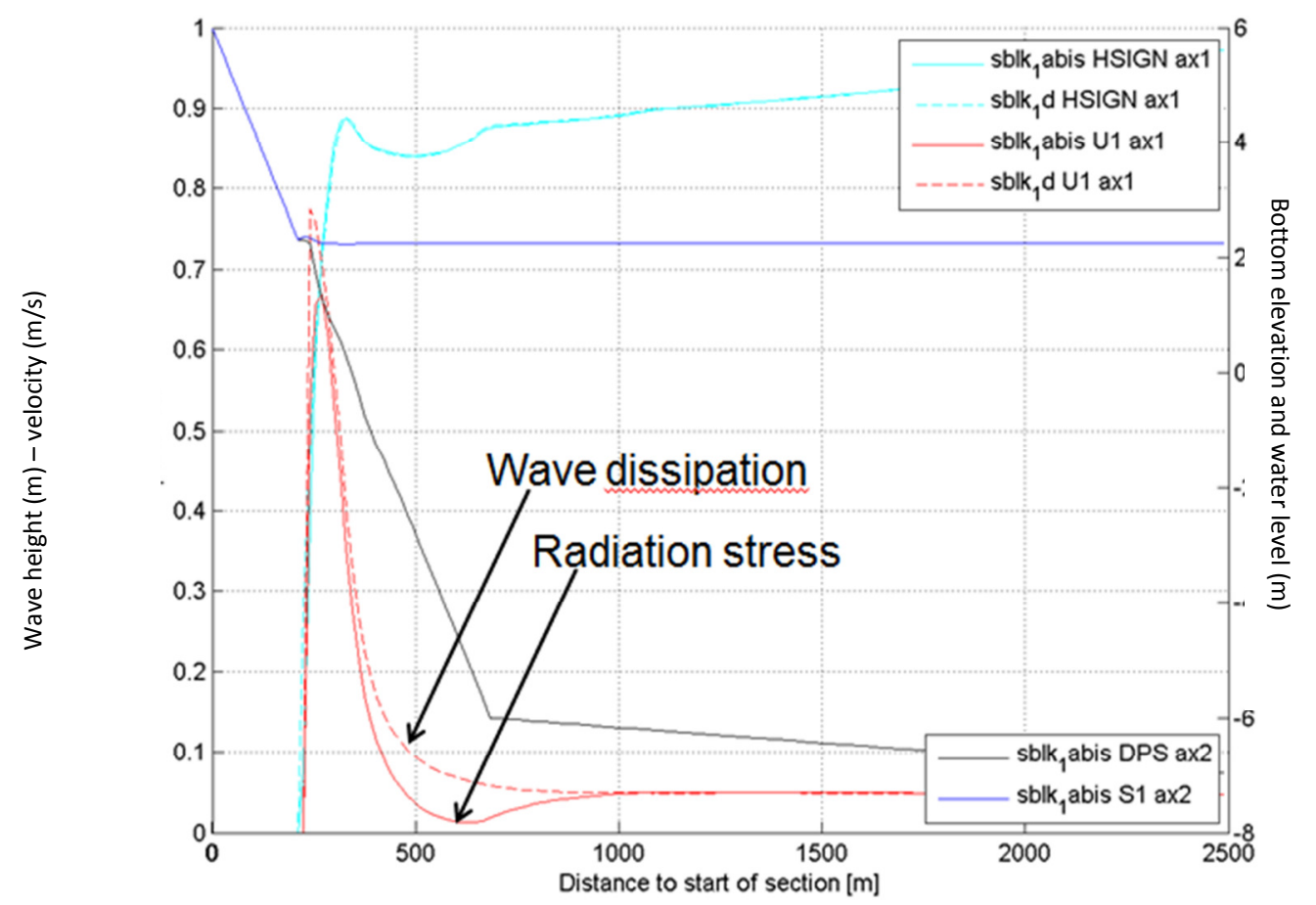

Figure 4 Wave induced currents using wave dissipation vs radiation stress theory

Two other effects may be worth mentioning when choosing the wave force theory. There is possibly a model bug in the computation of the orbital velocity, which is a factor $1.4(=\sqrt{2}$ ?) lower when using the dissipation theory than when using radiation stresses. Using wave dissipation instead of radiation stress further leads to reduced dissipation in the breaker zone, also with a factor 1.4 difference.

The morphology changes most for waves perpendicular to the coast. The wave-related bed-load and suspended transport factors have however to be reduced strongly to avoid the formation of an artificial beach berm due to a too high onshore transport (cf. Figure 5). A value of 0.1 instead of 1 is suggested for both parameters. A value of 0 seems to suppress all cross-shore changes in the case of a uniform coast.

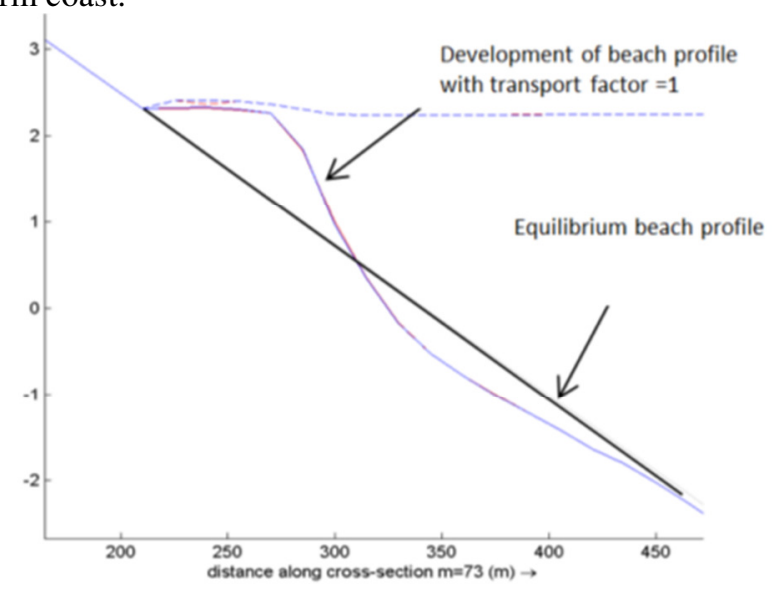

Figure 5 Development of cross shore profile in Delft3D 
The eddy viscosity and diffusivity influence the width of the zone of longshore current and related sediment transport. The default settings are considered to be too high. Respective values of 0.1 and 0.1 instead of 1 and $10 \mathrm{~m}^{2} / \mathrm{s}$ are judged to be more appropriate for coastal applications. Effects on depthaveraged velocities and sediment transport are much more pronounced in case of values above $1 \mathrm{~m}^{2} / \mathrm{s}$. Different viscosity and diffusivity settings between 0.1 and $1 \mathrm{~m}^{2} / \mathrm{s}$ give results which are strongly comparable. Both parameters are diffusive terms: the velocity and transport patterns become smoother for higher values.

\section{XBeach}

From thehe sensitivity analysis of the XBeach model a number of conclusions could be drawn.

Wave dissipation by bed friction appears to be the main calibration parameter and maybe should be included in the default settings (suggested value $\mathrm{fw}=0.05-0.1$ ). Wave dissipation by bottom friction is more effective near the surf zone in XBeach, which uses a Collins-type of friction, and works over long distances in Delft3D, which uses an empirical JONSWAP friction coefficient.

Other parameters, and in particular the viscosity, have only a limited effect on the results. A subgrid scale viscosity model like the one of Smagorinski is only expected to become important for coarser grids (>50 to $100 \mathrm{~m})$.

Onshore transport by wave asymmetry is important for the cross-shore sediment transport and morphology, and maybe should be included in the default settings as well (suggested value facua=0.10.15 ). Using a facua $=1$ results in onshore transport with the same order of magnitude as the offshore transport when using facua $=0.1$.

The effect of secondary parameters is hidden by the uncertainty arising from working with an instationary model : results vary from one simulation to the other, even after averaging over $30 \mathrm{~min}$ ( 225 waves of period $\mathrm{T}=8 \mathrm{~s}$ ). Averaging over a longer period is not realistic because of the tidal variation and the limited length of the wave record ( $2 \mathrm{~h}$ maximum).

The uncertainty due to the instationary character is presented in Table 2 . The relative variation is thus an under limit of possible model accuracy.

Table 2 Estimated variability of instationary model results ( $\mathrm{Hs}=1 \mathrm{~m}$, waves $45^{\circ}$ degrees to the coast)

\begin{tabular}{|l|l|l|}
\hline Parameter & Estimated absolute variation & Estimated relative variation \\
\hline Wave height $\mathbf{H}$ & $+/-5 \mathrm{~cm}$ & $+/-5 \%$ \\
\hline Wave direction $\boldsymbol{\theta}$ & $+/-4^{\circ}$ & $+/-10 \%$ \\
\hline Longshore current & $+/-0.05-0.1 \mathrm{~m} / \mathrm{s}$ & $+/-5-10 \%$ \\
\hline Cross-shore current & $+/-0.01-0.02 \mathrm{~m} / \mathrm{s}$ & $+/-10-15 \%$ \\
\hline Total longshore transport & $+/-0.5^{*} 10^{-4} \mathrm{~m}^{3} / \mathrm{s} / \mathrm{m}$ & $+/-20 \%$ \\
\hline Total cross-shore transport & $+/-1 * 10^{-5} \mathrm{~m}^{3} / \mathrm{s} / \mathrm{m}$ & $+/-20 \%$ \\
\hline
\end{tabular}

The variability of results arising from the instationary character is considerable. Long waves should not be turned off since radiation stresses seem to be computed in that module, although generated by short waves. Instead stationary waves may be applied at the boundary.

The flow boundary condition inland determines the cross-shore velocity profile in the entrance channel and influences the longshore velocity and sediment transport on both sides of the channel. A no flux wall and a tidal water level yield similar results..

\section{Delft3D vs XBeach}

Figure 6 compares the hydrodynamic results of XBeach and Delft3D for a case with $1 \mathrm{~m}$ heigh waves at the offshore boundary (of the overall Delft3D model resulting in smaller values at the XBeach boundary) and waves have a direction of $45^{\circ}$ towards the normal. The comparison shows that both match very well. Similar results are obtained for waves + tide combinations. 


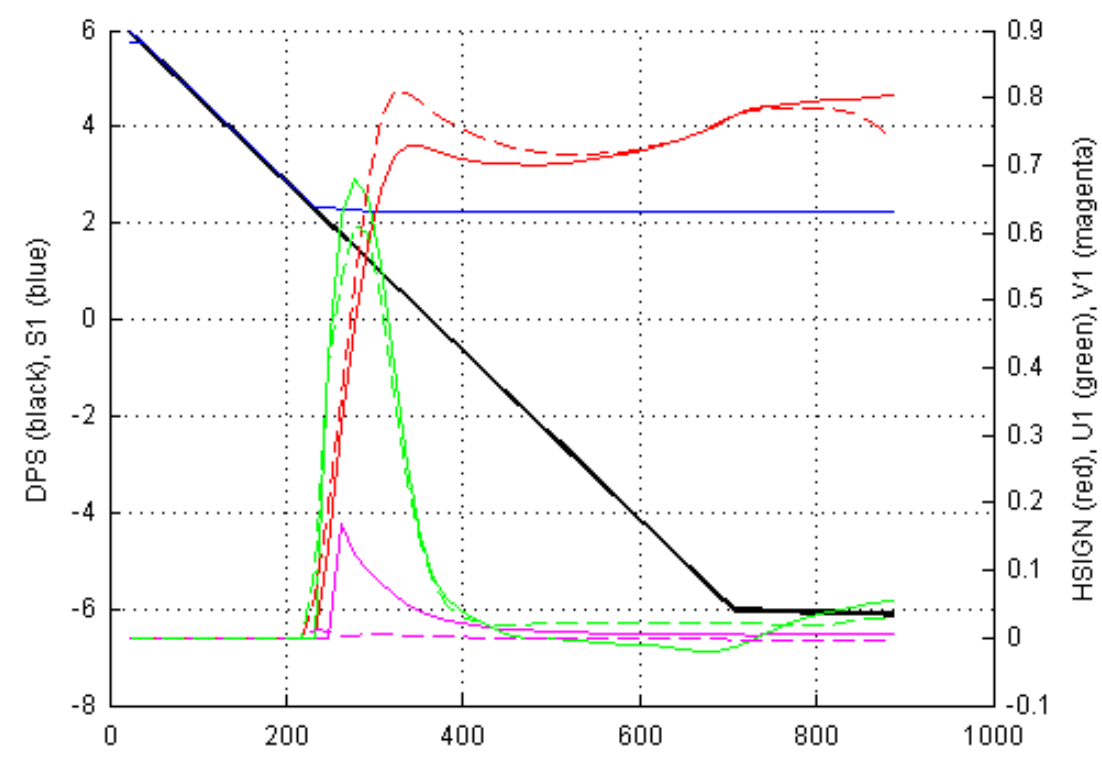

Figure 6 Comparison of the wave height (red), longshore current (green) and cross shore current (purple; Eulerian in Delft3D (only return flow), Lagrangian in XBeach) between Delft3D (full line) and XBeach (dotted line) (waves at $45^{\circ}$ to the normal)

The longshore sediment transport matches surprisingly well between the models, given the large differences in longshore velocity and wave direction observed, and the fact that sediment transport is a power function of the velocity. It may be a coincidence or it may have been calibrated to yield target transport rates. Both transport formulae are very similar: Delft3D uses the transport formulae of Van Rijn (1993) while XBeach uses the formula of Soulsby-Van Rijn (1997).

The cross-shore sediment transport in Delft3D depends strongly on the wave related factors for bed-load and suspended transport which makes a comparison arbitrary. In XBeach the suspended cross-shore transport is several times larger than the bed-load transport and both are directed offshore. The cross-shore sediment transport is dominant for waves normal to the coast and several times smaller than the longshore transport for a large incidence angle.

The instationary character of XBeach may manifest itself in situations in which a threshold of any kind is present, which is never exceeded in stationary models but may occasionally be exceeded in an instationary model. For this reason, XBeach is more likely to show its purpose in situations for which it has been designed for: dune erosion, breaching, overtopping and runup computations. Each of these cases by essence necessitates an instationary model, which allows water waves to occasionally reach places which are inaccessible in a stationary model, due to variations in water level induced by long waves.

The instationary character of XBeach also gives an indication of the hidden uncertainty which can be expected from the model results of a stationary model such as Delft3D. Another advantage of XBeach are its good default values, which allow to quickly set up a model and investigate a problem without beginning to tweak options. The same may however be said of Delft3D once experience has told which settings should ideally be used as default values.

XBeach may be used for long-term profile modelling thanks to its $1 \mathrm{D}$ option. In 2D however it is still limited in space due to the absence of deep-sea wave processes in its wave solver and due to memory issues during the generation of long waves time series to be applied at the boundaries.

$\mathrm{XBeach}$ is therefore recommended for coastal applications which require a moving land boundary or a realistic cross-shore profile, while Delft3D is recommended for applications in which a fixed coastline is sufficient and the details of the cross-shore behaviour are not crucial.

\section{STRUCTURES (GROYNES)}

The following two paragraphs (structures and morphological acceleration) describes two important items for coastal modeling, independent of the comparison between Delft3D and Xbeach. 
In XBeach the only way to incorporate groynes is by non-erodible hard layers, in Delft3D more options are available (most suitable are non-erodible hard layers, or weirs in FLOW/structues in WAVE). A weir stops the flow over a fraction of the water depth but not the waves, an obstacle does the opposite. By making the elements short, a sloping groyne can be represented with a combination of structures/weirs with varying crest levels, the shorter the elements the better the representation.

A combination of 2D weirs in FLOW and obstacles in WAVE compared to a hard layer in the bathymetry, results in comparable results. .

Quantitative differences mainly result from the locally different height of the structures and cannot be commented. To be comparable with XBeach, it was preferred to continue with non-erodible hard layers.

\section{USE OF A MORPHOLOGICAL ACCELERATION FACTOR}

It is possible to accelerate the morphology based on the different time scales of hydrodynamics and morphology (De Vriend et al, 1993). There are several ways to decouple the two (Roelvink, 2006,Lesser, 2009), Delft3D and XBeach for instance use a morphological acceleration factor (morfac) to multiply all bed level changes with this factor. For example, if a morfac of 10 is used, the erosion/sedimentation after each time step is multiplied by 10. If 1 tidal cycle is modeled with morfac 10, the erosion/sedimentation at the end represents the changes after 10 tides. Bathymetrical changes can strongly influence the wave parameters. Possibbly, a more frequent update of the wave height becomes necessary. In case of morfac 1, the wave simulation is updated every 20 minutes of the tide. In the case of morfac 10, the wave results are updated for a morphology that exists after a time representing 10 times the same 20 minutes of tide (e.g. 10x 20 minutes of high water conditions), and in the case of morfac 50, this is after a time representing 50 times 20 minutes ( $=16$ hours) of tide. In fact, when using a morphological acceleration factor, the communication time between FLOW and WAVE module should be made smaller, to get more frequent updates of the morphological and wave situation. This, however, also increases a lot the simulation time of the run (the stationary wave computation is the most time consuming). Calculations with different updating frequencies shows that the calculation time scales quasi perfectly with the updating frequency. Unless parallel processing is used, it does not make sense to increase morfac and increase the updating frequency equally.

Figure 7 compares the use of morfac 10 (10 tidal cycles simulated with 1 cycle) and 10 times morfac 1 (so effectively running 10 tidal cycles) for a case with a submerged groyne (crest $1 \mathrm{~m}$ above the bed), waves of $1 \mathrm{~m}, 45^{\circ}$ to the normal). Only minor differences are visible. The sedimentation behind the groyne can be explained by the fact that the current can go over the groyne, at the crest of the groyne, the flow is overloaded due to flow contraction (with sediment), which sedimentates downdrift.
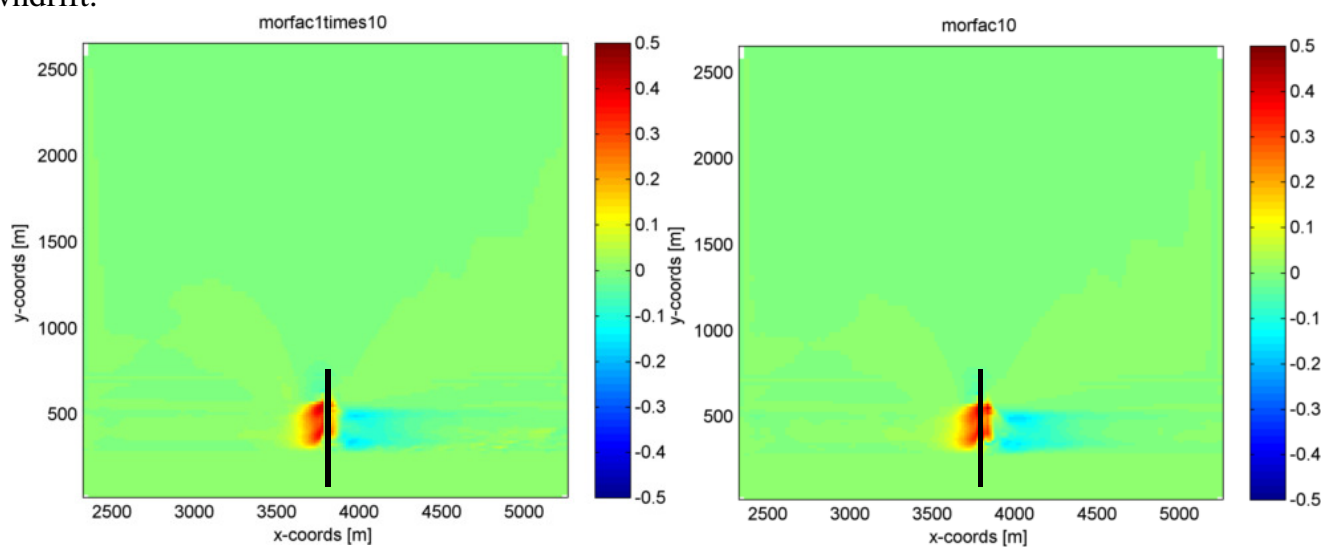

Figure 7 Comparison of morfac10 with 10 times morfac1

Figure 8 compares the use of morfac 50 (50 tidal cycles simulated with 1 cycle) and 5 times morfac 10 (so simulating (hydrodynamically) 5 tidal cycles, each representing (morphologically) 10 tidal cycles). Qualitatively the figures still correspond, but using morfac 10 seems to overestimate sedimentation and erosion. 


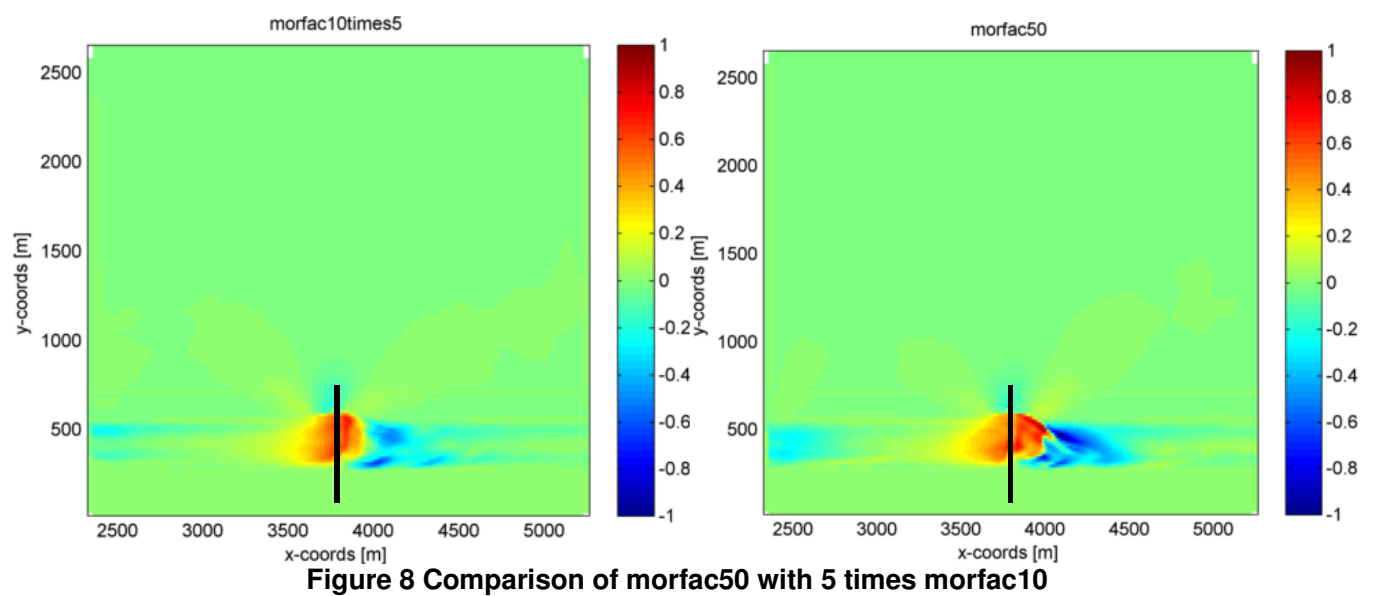

Figure 9 compares the use of morfac 200 (200 tidal cycles simulated with 1 cycle) and 4 times morfac 50 (so simulating (hydrodynamically) 4 tidal cycles, each representing (morphologically) 50 tidal cycles). The use of morfac 200 seems not realistic anymore, also qualitatively, important differences are visible (e.g. the zone of sedimentation behind the groin is much larger.

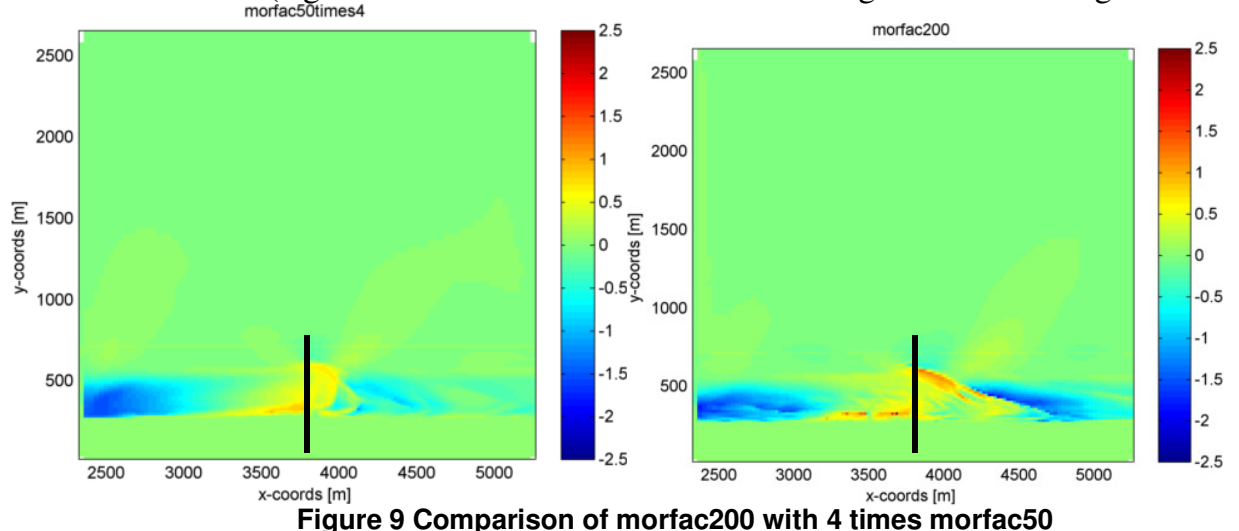

\section{CONCLUSIONS}

In this paper Delft3D and XBeach are compared for coastal morphological applications. Overall a good correspondence in waves and longshore (sediment) transport was found. Delft3D is necessary to model waves, currents and sediment transport in the offshore zone and to provide these boundary conditions to XBeach. Also for longshore transport Delft3D can be used. However, if the instationary character is important, only XBeach can be used. XBeach incorporates the important processes for cross shore transport. In 2D mode Delft3D fails for cross shore developments.

Also other conclusions could be derived: XBeach indicates that the randomness of waves results in a scatter of about $20 \%$ on the sediment transport. Structures (groynes, breakwaters) can be modeled using hard non-erodible layers. The use of morfac can accelerate calculations, however, this is limited since also the wave calculations should be done frequently enough.

\section{ACKNOWLEDGMENTS}

The authors acknowledge Coastal Division of the Flemish administration for partially funding this study.

\section{REFERENCES}

Booij, N., R.C. Ris and L.H. Holthuijsen. 1999. A third-generation wave model for coastal regions, Part I, Model description and validation, J. Geophys. Res. C4, 104, 7649-7666.

Brière, C. and Walstra, D.J. (2006). Modelling of bar dynamics. WL Delft Hydraulics report, project Z4099.00, prepared for Rijskwaterstaat - RIKZ, The Netherlands. 
Deltares 2010a. Delft3D-FLOW. Simulation of multi-dimensional hydrodynamic flow and transport phenomena, including sediments - User Manual. Version 3.04, rev. 11114. Deltares, Delft, The Netherlands.

Deltares 2010b. Delft3D-WAVE. Simulation of short-crested waves with SWAN - User Manual. Version 3.04, rev. 11114. Deltares, Delft, The Netherlands.

De Vriend, H.J., Zyserman, J., Nicholson, J, Roelvink, J.A., Pechon, P., and Southgate, H.N. (1993). Medium-term 2DH coastal area modelling. Coastal Engineering, 21, pp. 193-224.

Grasmeijer, B. 2002. Process-based cross-shore modelling of barred beaches. PhD thesis, pp.251, University of Utrecht, The Netherlands.

Holthuijsen, L., Booij, N. and Herbers, T. 1989. A prediction model for stationary, short-crested waves in shallow water with ambient currents, Coastal Eng. , 13, pp. $23\{54$.

Lesser, G.R. (2009). An approach to medium-term coastal morphological modeling. PhD dissertation, Unesco-IHE Institute for Water Education and Delft University of Technology, The Netherlands.

Reniers, A.J.H.M., E.B. Thornton, T. Stanton and J.A. Roelvink. 2004. Vertical flow structure during Sandy Duck: Observations and Modeling. Coastal Engineering, Volume 51, Issue 3, May 2004, Pages 237-260

Ris, R.C. 1997. Spectral Modelling of Wind Waves in Coastal Areas (Ph.D. Dissertation Delft University of Technology), Communications on Hydraulic and Geotechnical Engineering, Report No. 97-4, Delft.

Roelvink, J.A. 1993. Dissipation in random wave groups incident on a beach. Coastal Eng., 19 pp. 127-150.

Roelvink J.A. (2006). Coastal morphodynamic evolution techniques. Coastal Engineering, vol. 53, pp 277-287.

Roelvink, D., Reniers, A., van Dongeren, A., van Thiel de Vries, J., Lescinsky, J. and McCall, R. (2009). Modelling storm impacts on beaches, dunes and barrier islands. Coastal Engineering, vol. 56, pp. 1133-1152.

Ruessink, B.G., Kuriyama, Y., Reniers, A.J.H.M., Roelvink, J.A., and Walstra, D.J.R. 2007. Modeling cross-shore sandbar behavior on the timescale of weeks. J. Geophys. Res., 112, F03010.

Soulsby, R.L. 1997. Dynamics of marine sands : a manual for practical applications. Thomas Telford Publications, 249 p.

Van Rijn, L.C. 1993. Principles of Sediment Transport in Rivers, Estuaries and Coastal Seas. Aqua Publications, Amsterdam, The Netherlands.

Unesco-IHE, Deltares, TU Delft. 2009. XBeach model description and manual. Report Z4175

Walstra, D.J.R., Reniers, A.J.H.M., Ranasinghe, R., Roelvink, J.A., and Ruessink, B.G. 2012. On bar growth and decay during interannual net offshore migration, Coastal Engineering Volume 60,

Zimmermann, N.; Mathys, M.; Trouw, K.; Delgado, R.; Verwaest, T.; Mostaert, F. 2012. Scientific support regarding hydrodynamics and sand transport in the coastal zone: Simplified Blankenberge case: comparison of Delft3D and XBeach model results. Version 2_0. WL Rapporten, 744_30. Flanders Hydraulics Research \& IMDC: Antwerp, Belgium. 